This is a revised personal version of the text of the final journal article, which is made available for scholarly purposes only, in accordance with the journal's author permissions. The full citation is:

Yirong, C., Heaven, S., \& Banks, C. J. Effect of a Trace Element Addition Strategy on Volatile Fatty Acid Accumulation in Thermophilic Anaerobic Digestion of Food Waste. Waste and Biomass Valorization, 1-12. DOI 10.1007/s12649-014-9327-2

(http://link.springer.com/article/10.1007/s12649-014-9327-2)

\title{
Effect of a trace element addition strategy on volatile fatty acid accumulation in thermophilic anaerobic digestion of food waste
}

\section{Yirong, S. Heaven and C. J. Banks}

Faculty of Engineering and the Environment, University of Southampton, Southampton, SO17 1BJ, UK

(E-mail: cy1g09@soton.ac.uk; C.J.Banks@ soton.ac.uk, and sh7@ soton.ac.uk)

Corresponding author:

Chaowana Yirong

Faculty of Engineering and the Environment, University of Southampton, Southampton, SO17 1BJ, UK

E-mail: cy1g09@soton.ac.uk

Tel. +44 (0)2380 592845

Fax +44 (0)2380 677519 


\begin{abstract}
Purpose: A trace element supplementation strategy previously shown to be effective in mesophilic conditions was tested for thermophilic digestion of source segregated domestic food waste.

Method: Inoculum from a mesophilic anaerobic digester treating municipal wastewater biosolids was successfully acclimated to thermophilic temperature $\left(55^{\circ} \mathrm{C}\right)$ with food waste as a substrate. Four laboratory-scale digesters were maintained at a loading of $2 \mathrm{~g} \mathrm{VS} \mathrm{l}^{-1}$ day $^{-1}$ with one pair receiving trace elements (TE) supplementation. Two more pairs of digesters were incrementally loaded to 3 and $4 \mathrm{~g} \mathrm{VS}^{-1} \mathrm{day}^{-1}$, respectively, and also received TE. Results: All digesters performed well for the first 3-4 months of operation, but volatile fatty acid (VFA) concentrations in those without TE showed no recovery from an initial small accumulation. On continued operation, VFA concentrations increased in all digesters, especially those at higher loading rates or without TE supplementation, reaching $>30 \mathrm{~g} \mathrm{l}^{-1}$. Under these meta-stable conditions, a deliberate disturbance to daily feeding (cessation then resumption) led to acetic acid accumulation, a fall in $\mathrm{pH}$ and a sharp increase in the ratio of partial to intermediate alkalinity. Increases in VFA corresponded to an increasing total ammonia nitrogen concentration which appeared to become inhibitory at $\sim 2500 \mathrm{mg} \mathrm{N} \mathrm{I}^{-1}$. Conclusions: While TE supplementation delayed the onset and reduced the rate of VFA accumulation, it was unable to sustain stable digestion of this substrate in thermophilic conditions.
\end{abstract}

Keywords Volatile fatty acids; food waste; thermophilic; ammonia; trace elements 


\section{$1 \quad$ Introduction}

Anaerobic digestion is the degradation of organic material in the absence of oxygen to produce biogas (a mixture of methane, carbon dioxide and trace amounts of other gases), and a residual stabilised digestate. The process is becoming a popular technology because of its ability to produce renewable energy from a wide variety of organic wastes from municipal, agricultural and industrial sources, while allowing nutrient recovery through application of the digestate to land. The European Landfill directive (99/31/EC), which requires the diversion of biodegradable municipal waste from landfill, has led to a growing number of schemes for the collection of source segregated food waste from domestic and commercial properties. Early digestion trials with this material, however, showed accumulation of volatile fatty acids (VFA) over extended run times in both mesophilic and thermophilic digestion systems [1]. Similar observations were made in a full-scale thermophilic digester treating source segregated restaurant and catering waste [2], and in the UK Government's food waste demonstration AD plant in Ludlow, UK [3]; and have also been demonstrated in laboratoryscale digesters $[4,5]$.

Source segregated domestic food waste is not the only food industry substrate that can lead to VFA accumulation: this has also been observed with coffee waste [6]; pet food [7]; and by a number of authors with different types of slaughterhouse wastes [8-10]. VFA accumulation in the digester is believed to be caused by high ammonia concentrations, with toxic levels being variously reported e.g. as $\left(\mathrm{mg} \mathrm{N}^{-1}\right) 2,000$ [11]; >3,000 [12]; 4,000 [13] and 5,000 [14]. It is also recognised that higher temperatures lead to more severe ammonia toxicity at the same $\mathrm{pH}$ [15], and that the toxicity threshold is lower for acetoclastic than for hydrogenotrophic methanogens $[14,15]$.

It has been shown that in mesophilic conditions accumulation of VFA can be prevented by supplementing with selected trace elements [17-20]. Mesophilic food waste digesters supplemented with trace elements have been shown to operate with good gas production and low VFA concentrations at ammonia concentrations in excess of $6000 \mathrm{mg} \mathrm{l}^{-1}$, but with a purely hydrogenotrophic methanogenic population; and a mechanism by which trace element addition can prevent VFA accumulation at high ammonia concentrations has been put forward [18]. Selenium, which is present only in low concentrations in food waste, has been shown to be essential in preventing propionic acid accumulation by providing the co-enzymes 
necessary for the reduction of formate, one of the metabolic products of propionate degradation. At higher organic loading rates (OLR) additional cobalt is also required. This is thought to be necessary as in these high ammonia conditions all of the organic carbon is converted to carbon dioxide through syntrophic acetate oxidation by the reverse WoodsLjungdahl pathway; in conjunction with the reduction of carbon dioxide to methane by the hydrogenotrophic route, this leads to an increase in co-enzyme demand. Where formate oxidation does not occur there is an accumulation of propionic acid and other longer-chain VFAs, leading eventually to a fall in $\mathrm{pH}$ and cessation of methanogenesis [18].

The current study investigated the extent to which a trace element addition strategy successfully applied in mesophilic conditions could prevent VFA accumulation in thermophilic digesters operating on source segregated food waste, in conditions of increasing ammonia concentration resulting from the addition of this nitrogen-rich feedstock.

\section{$2 \quad$ Materials and methods}

Feedstock. A single representative batch of approximately $200 \mathrm{~kg}$ of source segregated domestic food waste was collected from the South Shropshire digestion facility at Ludlow, UK. The material was first taken out of biodegradable plastic collection bags and any nonbiodegradable contaminants were removed. It was then homogenised using a macerating grinder (S52/010 Waste Disposer, IMC Limited, UK), mixed thoroughly and packed into 4litre plastic storage containers then frozen. The frozen feedstock was thawed before use, and stored at $4{ }^{\circ} \mathrm{C}$ for no more than 1 week.

Digesters. The eight digesters used each had a 5-litre capacity with a 4-litre working volume, and were constructed of PVC tube with gas-tight top and bottom plates. The top plates were fitted with a gas outlet, a feed port sealed with a rubber bung, and a draught tube liquid seal through which an asymmetric bar stirrer was inserted with a $40 \mathrm{rpm}$ motor mounted directly on the top plate. Digestate temperature was controlled at $55^{\circ} \mathrm{C}$ by circulating water from a thermostatically-controlled bath through a heating coil around the digesters, with occasional manual checking of digester temperatures. Biogas was measured using tipping-bucket gas counters with continuous data logging [21], and reported gas volumes are corrected to standard temperature and pressure of $0{ }^{\circ} \mathrm{C}, 101.325 \mathrm{kPa}$. Semi-continuous operation was achieved by removing digestate through an outlet port in the base plate before adding feed via 
the hole in the top plate: this was done on a daily basis throughout the experimental period unless noted. The digesters were seeded with inoculum from a mesophilic digester treating municipal wastewater biosolids (Millbrook Wastewater Treatment Plant, Southampton, UK) and acclimatised to $55{ }^{\circ} \mathrm{C}$ without feeding for 14 days, then fed at an incremental loading starting at $0.01 \mathrm{~g} \mathrm{VS} \mathrm{l}^{-1}$ day $^{-1}$ and increasing to $0.23 \mathrm{~g} \mathrm{VS} \mathrm{l}^{-1}$ day $^{-1}$ over 20 days. On day -1 the contents of all eight digesters were mixed and redistributed to ensure a common start point.

Experimental design. Feeding of all digesters started on day 1 at an organic loading rate (OLR) of $1 \mathrm{~g} \mathrm{VS} \mathrm{l}^{-1}$ day $^{-1}$ which was gradually increased to $2 \mathrm{~g} \mathrm{VS}^{-1}$ day $^{-1}$ by day 32 (see Figure 1a). In two pairs of digesters the OLR was then gradually increased to 3 (by day 82) and $4 \mathrm{~g} \mathrm{VS}^{-1}$ day $^{-1}$ (by day 103). The remaining two pairs continued at an OLR of $2 \mathrm{~g} \mathrm{VS}^{-1}$ day $^{-1}$. Once each pair of digesters reached its target OLR this was maintained until day 158, after which feeding was stopped or resumed depending on individual digester conditions, as described in the results section: monitoring of the digesters was continued to day 250 .

All of the digesters with the exception of one pair at $2 \mathrm{~g} \mathrm{VS} \mathrm{l}^{-1}$ day $^{-1}$ were supplemented with trace elements (TE). TE supplemented digesters received an initial addition of $1 \mathrm{ml} \mathrm{l}^{-1}$ of a solution containing $\left(\mathrm{g} \mathrm{l}^{-1}\right)$ : Aluminium (Al) 0.1, Boron (B) 0.1, Cobalt (Co) 1.0, Copper $(\mathrm{Cu})$ 0.1, Iron (Fe) 10.0, Manganese (Mn) 1.0, Nickel (Ni) 1.0, Zinc (Zn) 1.0, Molybdenum (Mo) 0.1, Selenium (Se) 0.1, Tungsten (W) 0.1 (ref). They then received a daily addition of $1 \mathrm{ml}$ of this solution for every litre of digestate removed to maintain the initial concentration. Digesters are named according to the operating conditions, as follows: digester TE-2-A is supplemented with TE and is at OLR $2 \mathrm{~g} \mathrm{VS} \mathrm{l}^{-1}$ day $^{-1}$, while A and B represent the duplicate digesters.

Analytical Methods. Total solids (TS) and volatile solids (VS) were measured using standard method $2540 \mathrm{G}$ [22]. $\mathrm{pH}$ was measured with a combination glass electrode calibrated in buffers at $\mathrm{pH}$ 4, 7 and 9. Chemical oxygen demand (COD) was determined by adapting the closed reflux titrimetric standard method $5220 \mathrm{C}$ [22]. Alkalinity was measured by titration with $0.25 \mathrm{~N} \mathrm{H}_{2} \mathrm{SO}_{4}$ to endpoints of $\mathrm{pH} 5.75$ and 4.3, allowing calculation of total (TA), partial (PA) and intermediate alkalinity (IA) [23]. Total Kjeldahl Nitrogen (TKN) was determined using a Kjeltech block digester with total ammonia nitrogen measured by steam distillation unit according to the manufacturer's instructions (Foss Ltd, Warrington, UK). Volatile fatty acids (VFA) were quantified in a Shimazdu GC-2010 gas chromatograph (Shimadzu, Milton 
Keynes, UK), using a flame ionization detector and a capillary column type SGE BP-21. Biogas composition $\left(\mathrm{CH}_{4}\right.$ and $\left.\mathrm{CO}_{2}\right)$ was determined using a Varian star $3400 \mathrm{CX}$ Gas Chromatograph, and calibrated with a standard gas with $65 \mathrm{CH}_{4}$ and $35 \mathrm{CO}_{2}$ (v/v). Elemental composition $(\mathrm{C}, \mathrm{H}, \mathrm{N})$ content was determined using a FlashEA 1112 Elemental Analyzer, (Thermo Finnigan, Italy) based on the manufacturer's instructions using methionine, Lcystine and sulphanilamide as standards. Samples for trace element determination $(\mathrm{Co}, \mathrm{Fe}$, $\mathrm{Ni}, \mathrm{Mo}, \mathrm{Se}$ ) were extracted in nitric acid and sent to an external laboratory for analysis by ICP-MS (LGC, Teddington, UK).

Free ammonia nitrogen (FAN) concentrations were calculated based on temperature and $\mathrm{pH}$, according to Hansen et al. [24].

\section{$3 \quad$ Results and discussion}

\subsection{Food waste characteristics}

The characteristics of the single batch of food waste used throughout the trial are shown in Table 1. Values are closely similar to those reported elsewhere in the literature for source segregated food waste of this type $[5,25,26]$.

\subsection{Digester start up (day 1 - 45)}

When feeding began on day 1 at an OLR of $1 \mathrm{~g} \mathrm{VS}^{-1}$ day $^{-1}$ (Figure 1a), all of the digesters receiving TE supplementation responded in a similar way. There was a small but distinct peak in acetic acid of 600-900 $\mathrm{mg}^{-1}$ in the first 2-3 days, which declined by day 10 (Figure 2). This was followed by a second peak in propionic acid of $\sim 1000 \mathrm{mg} \mathrm{l}^{-1}$, which in turn declined to give a total VFA concentration $\leq 500 \mathrm{mg}^{-1}$ by day 35 . By this time the applied OLR had reached $2 \mathrm{~g} \mathrm{VS}^{-1}$ day $^{-1}$ (Figure 1a), with a specific methane production of around $0.42 \mathrm{l} \mathrm{CH}_{4} \mathrm{~g}^{-1} \mathrm{VS} \mathrm{day}^{-1}$ in all digesters. Only one digester (TE-2-A) showed slightly different behaviour in terms of its VFA profile (Figure 2a), with a higher propionic acid peak of around $1600 \mathrm{mg}^{-1}$ that had only fallen to around $400 \mathrm{mg} \mathrm{l}^{-1}$ by day 38 , after which the concentration began to rise again.

It is also worth noting that during this period the $\mathrm{pH}$ in all digesters fell from $\sim 8.3$ to $\sim 7.8$ by 
day 17 (Figure $1 \mathrm{~b}$ ), and then recovered, eventually reaching $\sim 8.5$. The total ammonia nitrogen (TAN) concentration also fell slightly from an initial value of $\sim 1.8 \mathrm{~g} \mathrm{~N}^{-1}$ to $1.5 \mathrm{~g} \mathrm{~N}$ $1^{-1}$ by day 17 (Figure 1c), then began to rise. This change is likely to reflect a period of rapid growth in the microbial population, during which the rate of nitrogen uptake into cell biomass temporarily exceeds the rate of breakdown of organic nitrogen in the feedstock to ammonia. The increase in TAN and fall in VFA concentration were reflected in the IA/PA ratio which fell from $\sim 0.9$ to $\sim 0.5$ (Figure 1d). Based on the above performance parameters, by day 45 all of the digesters with the possible exception of TE-2-A were considered to be in a stable state at the base OLR of $2 \mathrm{~g} \mathrm{VS}^{-1}$ day $^{-1}$ and to have successfully acclimated to thermophilic conditions with a specific methane production of around $0.401 \mathrm{CH}_{4} \mathrm{~g}^{-1} \mathrm{VS}$ day $^{-1}$ (Figure 1e).

In the two digesters without TE addition the pattern of VFA accumulation was slightly different, as the early increase in propionic acid did not return to a baseline value. This was especially pronounced in one of the pair of digesters, which showed no fall in VFA concentration (Figure $2 \mathrm{~g}$ and $\mathrm{h}$ ); in the second digester of the pair there was a reduction in propionic acid to $\sim 800 \mathrm{mg} \mathrm{l}^{-1}$ between days 30-40, after which the increase in concentration resumed. In all other respects, including specific methane production, acclimatisation of these digesters also appeared to be successful and similar to that in the TE supplemented digesters (Figure 1).

The rate of increase in propionic acid from day 1-20 was very similar in all digesters at around $36 \mathrm{mg}^{-1}$ day $^{-1}$ (Figure 1f), with the TE supplemented digesters distinguished from the unsupplemented ones only by the marked fall in concentration after day $\sim 25$. Iso-valeric acid concentrations, initially around $220 \mathrm{mg} \mathrm{l}^{-1}$, fell sharply after day $20-30$ to $<10 \mathrm{mg}^{-1}$ in all digesters (Figure 2).

The above results clearly indicated that trace element supplementation had a beneficial effect during the start-up phase of digestion, with a reduction in the initial accumulation of VFA.

\subsection{Main experimental period (day 46 - 250)}

In the period following start-up TAN concentrations in all digesters increased from the initial value of $\sim 1.8 \mathrm{~g} \mathrm{~N}^{-1}$ to between $5-6 \mathrm{~g} \mathrm{~N}^{-1}$ (Figure 3a), as expected due to the high nitrogen content of the incoming feedstock. Changes in alkalinity reflected this, with TA increasing 
from $\sim 8 \mathrm{~g} \mathrm{CaCO}_{3} \mathrm{l}^{-1}$ to $\sim 23.5$ and $\sim 19.7 \mathrm{~g} \mathrm{CaCO}_{3} \mathrm{l}^{-1}$ in digesters with and without TE supplementation, respectively (Error! Reference source not found.b). The VS concentration rose fairly steadily from 2.6 to $3.8 \mathrm{~g} \mathrm{VS}^{-1}$ between day $\sim 40-90$ and VS content stabilised at around $75 \%$ of TS (Figure 3c and d) in all digesters.

\subsubsection{TE supplemented digesters}

Up until day 158, when there was a change in feeding regime, all of the TE supplemented digesters continued to operate well, with volumetric biogas production increasing in proportion to sequential load increases and specific methane production stabilising at around $0.43 \mathrm{l} \mathrm{CH}_{4} \mathrm{~g}^{-1} \mathrm{VS}_{\text {day }}{ }^{-1}$ (Figure $4 \mathrm{a}$ and $\mathrm{b}$ ).

VFA profiles for each digester during the whole experimental run are shown in Figure 5. As can be seen, there was some variability between paired digesters as well as between those at different loadings. The trends in behaviour, however, were similar. In all of the TE supplemented digesters there was a rise in total VFA to above $2000 \mathrm{mg} \mathrm{l}^{-1}$ from around day 70 , with increasing concentrations of both acetic and propionic acid. At this point the TAN (Figure 3a) in the digesters had reached $2500 \mathrm{mg} \mathrm{N}^{-1}$, with FAN around $1100 \mathrm{mg} \mathrm{N}^{-1}$. By day 150 the digesters at OLR 3 and $4 \mathrm{~g} \mathrm{VS} \mathrm{l}^{-1}$ day $^{-1}$ (TE-3-A\&B and TE-4-A\&B, respectively) had TAN concentrations of around $4.2 \mathrm{~g} \mathrm{~N} \mathrm{l}^{-1}$ (FAN $\geq 2000 \mathrm{mg} \mathrm{N}^{-1}$ ) and an accumulated total VFA of 15-20 $\mathrm{g} \mathrm{l}^{-1}$, with propionic acid accounting for about $10 \mathrm{~g} \mathrm{l}^{-1}$ of this (Figure 5a-d). It was clear from this that the TE supplementation strategy adopted had not been successful in preventing VFA accumulation in thermophilic conditions.

Earlier studies $[1,2]$ had shown that thermophilic food waste digesters could operate for long periods at even higher VFA concentrations, but may be liable to sudden failure if a change in conditions results in the buffering capacity of the system being exceeded, with a subsequent fall in $\mathrm{pH}$, leading to cessation of methanogenesis and 'souring' of the digester. At day 158 therefore, feeding of all digesters was stopped to see whether they were able to reduce the total VFA concentration and how they would respond to a cessation of loading. In response to this the acetic acid concentrations fell, but there was little or no reduction in VFA of higher carbon chain lengths (Figure 5a-d), indicating some blockage in this metabolic route, and the total VFA concentration was largely unaffected (Figure 4g). Only the digesters at OLR $3 \mathrm{~g}$ $\mathrm{VS}^{-1}$ day $^{-1}$ showed a fall in iso-valeric concentration of $\sim 1 \mathrm{~g} \mathrm{l}^{-1}$, which was more rapid in 
TE-3-A than TE-3-B.

Feeding of the four digesters at OLR 3 and $4 \mathrm{~g} \mathrm{VS}^{-1}$ day $^{-1}$ began again on day 190 at a reduced OLR of $1 \mathrm{~g} \mathrm{VS} \mathrm{l}^{-1}$ day $^{-1}$ and immediately resulted in an accumulation of acetic acid, taking the total VFA to $30-35 \mathrm{~g} \mathrm{l}^{-1}$ by day 210 . At the same time the IA/PA ratio rose sharply (Figure $4 \mathrm{e}$ ) and in the following days $\mathrm{pH}$ in three of the digesters fell below $\sim 7$ (Figure $4 \mathrm{f}$, TE-3-B, TE-4-A\&B), and feeding of them was stopped. During the period of feeding there had been no significant resumption in volumetric gas or specific methane production (Figure $4 \mathrm{a}$ and $\mathrm{b}$ ). After cessation of feeding the second time one of the digesters showed some reduction in acetic acid and total VFA (TE-4-B, Figure 5d), but concentrations in the others remained high (Figure 5a, b and c). These results may indicate inhibition of the acetoclastic methanogens by TAN which was present in concentrations $>5000 \mathrm{mg} \mathrm{N}^{-1}$; and/or inhibition by VFA $[14,28]$. The $\mathrm{pH}$ in the fourth digester remained at $~ 7.5$ and feeding continued at $1 \mathrm{~g}$ $\mathrm{VS}^{-1}$ day $^{-1}$ which allowed a short-term reduction in acetic acid concentration (TE-3-A, Figure 5a) and some recovery in gas production and methane concentration (Figure $4 \mathrm{a}, \mathrm{b}$ and c).

Feeding of the digesters at OLR $2 \mathrm{~g} \mathrm{VS}^{-1}$ day $^{-1}$ was also stopped on day 158 but was restarted after 3 days, and both digesters initially responded by resuming gas production as before. In the digester with the higher VFA accumulation (TE-2-A, Figure 5e) this was not sustained, with a rapid fall in gas production between days 179 to 182 (Figure $4 \mathrm{a}$ and b) accompanied by a sharp increase in acetic acid concentration and a step change in IA/PA ratio (Figure 4e). In the digester with the lower VFA accumulation the $\mathrm{pH}$ and IA/PA ratios remained steady, despite the very high FAN concentration (Figure 4e-h). Gas production in this digester continued for a longer period, but began to decline from around day 220 (Figure $4 \mathrm{a}$ and $b)$.

It is interesting to note that until day 158 these digesters were continuing to function well in terms of specific and volumetric gas production despite IA/PA ratios of around 1. This supports view that an IA/PA ratio of 0.9 should be regarded as the upper limit for stability [29], rather than the 0.3 originally proposed [23]. This ratio will depend on the buffering capacity in a digester, and it is likely that the high TAN concentrations are themselves able to buffer a higher VFA concentration before the $\mathrm{pH}$ falls to a level at which methanogenesis is inhibited. Despite the slow accumulation of VFA, it is clear that there is a steady flow of 
carbon through to gaseous products, equivalent to a typical specific methane yield for the feedstock. It appears, however, that the digesters are in a meta-stable condition rather than in a fully stable operational state.

\subsubsection{Digesters without TE supplementation}

In contrast to the TE supplemented digesters, specific methane production in the unsupplemented digesters started to decrease from about day 70 , and by day $~ 140$ was falling rapidly (Figure 4b), with an IA/PA ratio above 1. Digester noTE-2-A showed an almost continuous rise in VFA concentration from the start of feeding, while digester noTE-2-B again showed an intermediate profile with some similarity to that of the TE supplemented digesters (Figure $5 \mathrm{~h}$ ). In both cases, however, the rates of VFA accumulation in the unsupplemented digesters (132 and $175 \mathrm{mg} \mathrm{l}^{-1}$ day $^{-1}$ in noTE-2-A and noTE-2-B, respectively) were considerably higher than in the TE supplemented digesters at the same OLR (88 and $88 \mathrm{mg} \mathrm{l}^{-1}$ day $^{-1}$ in TE-2-A and TE-2-B, respectively) (Figure 6).

On cessation of feeding on day 158 the acetic acid concentration in both unsupplemented digesters fell, causing a fall in total VFA. The response to resumption of feeding at a reduced OLR of $1 \mathrm{~g} \mathrm{VS}^{-1}$ day $^{-1}$ was the same as in the TE supplemented digesters, however, with a sharp rise in acetic acid concentration (Figure $5 \mathrm{~g}$ and $\mathrm{h}$ ) and in IA/PA ratio and a dramatic fall in $\mathrm{pH}$ (Figure $4 \mathrm{e}$ and $\mathrm{f}$ ). After feeding stopped around day 210 no reduction in VFA concentrations occurred.

\subsection{Overall discussion}

It is clear from the above results that while the addition of trace elements did delay the onset of propionic acid accumulation and reduce the rate of VFA accumulation, it was unable to prevent it at the TE concentrations used. It is therefore unlikely that a population change occurs within the digester that allows the system to operate at elevated TAN concentrations, as appears to be the case in mesophilic systems. This is supported by other work showing that mesophilic anaerobic digestion recovered from acidification after adding $\mathrm{Ni}, \mathrm{Co}$, and $\mathrm{Fe}$ of $0.04,0.16$, and $5.2 \mathrm{mg}^{-1}$ of organic solid waste; whereas this did not work with thermophilic anaerobic digestion [30]. The bioavailability of the trace elements present was not checked in the current work, but this may be critical [31], and may differ under mesophilic and 
thermophilic conditions. Qiang et al. [32] identified the trace element requirements ( $\mathrm{Ni}, \mathrm{Co}$, $\mathrm{Fe}$ ) for stable thermophilic digestion of low nitrogen food waste, with digester ammonia concentrations below $1200 \mathrm{mg} \mathrm{N}^{-1}$. In the current study the detrimental effects of ammonia appeared to become evident at around $2500 \mathrm{mg} \mathrm{N}^{-1}$ (FAN $\sim 1100 \mathrm{mg} \mathrm{N}^{-1}$ ). This is below the inhibitory TAN concentration observed in mesophilic digesters operating on the same substrate [1], but corresponds to the FAN inhibition threshold found e.g. by Hansen et al. [24]. This threshold may also reflect the degree of acclimation of the inoculum to high ammonia concentrations: Hashimoto [33] observed that ammonia inhibition began at about $2.5 \mathrm{~g} \mathrm{~N}^{-1}$ and $4.0 \mathrm{~g} \mathrm{~N}^{-1}$ for unacclimated and acclimated thermophilic methanogens, respectively.

FAN cannot be directly measured but is calculated from the TAN concentration, temperature and $\mathrm{pH}$. From Figure 5 it can be seen that observed peaks and troughs in FAN concentration in all digesters reflected the changes in acetic acid concentration, with increasing FAN associated with a reduction in acetic acid and vice versa. In contrast the other VFA species showed little or no relationship to FAN, and it is therefore likely that acetic is the main acid responsible for small changes in $\mathrm{pH}$ that influence the FAN concentration. Once VFA of higher carbon chain-lengths than propionic acid had appeared, they showed little or no response to changes in feeding (Figure 5).

The inverse relationship between acetic acid and FAN concentrations is interesting, as acetoclastic methanogenesis is thought to be most sensitive to FAN. The accumulation of acetic acid as a result of FAN inhibition could reduce the proportion of FAN to a point where the acetoclastic pathway is less inhibited, leading to an increase in methanogenesis by this pathway; the resulting decrease in acetic acid concentration then leads to an increase in FAN and the return of inhibitory conditions. This mechanism may account for the slow oscillations in acetic acid concentration seen in all digesters where inhibition is first occurring during the period of continuous feeding. On the other hand, subsequent major peaks in acetic acid concentration after the cessation and resumption of feeding indicate the failure of acetate degradation by both acetoclastic methanogenesis and acetate oxidation.

In the current work trace element addition prevented or reduced the accumulation of propionic acid in the start-up period (Figure 2), indicating that the mechanism proposed for mesophilic conditions of promoting formate reduction through selenium addition may be 
applicable here [18]; the beneficial effect, however, is subsequently outweighed by factors such as the increasing TAN and FAN concentrations. The intermediate behaviour of two of the digesters, one with TE supplementation and one without (TE-2-A and noTE-2-B), suggests that the system is finely balanced and may be influenced by small variations and interactions between a range of factors, of which trace element availability is only one. While the remaining pairs of digesters showed similar trends there were also differences in their responses to changes such as rising TAN concentrations and the cessation or reintroduction of feeding. Variations of this type often occur in stressed biological systems, where many different factors can affect the exact date of onset and mode of failure, and may be regarded as a form of the Anna Karenina principle [27]. The results confirmed, however, that trace element supplementation can offer only limited protection at high TAN concentrations in thermophilic conditions, and give further support to previous findings that mesophilic and thermophilic digester populations behave in different ways under these conditions. It is clear that the switch in metabolic route to hydrogenotrophic methanogenesis that allows stable operation of mesophilic food waste digestion above the inhibitory threshold of TAN or FAN for acetoclastic methanogenesis does not occur in thermophilic conditions. The prevention of propionic acid accumulation by promotion of formate reduction may not function in thermophilic systems because the organisms capable of carrying this out are not tolerant of the higher temperatures; or the digestion may simply fail because hydrogenotrophic methanogenesis is also inhibited at these TAN concentrations, resulting in the hydrogen accumulation and feedback inhibition of formate and propionate degradation.

\section{Conclusions}

Digestion of food waste results in high concentrations of ammonia that can lead to the accumulation of volatile fatty acids, but previous research has shown that under mesophilc conditions this problem can be resolved by the addition of a specific combination of trace elements. In thermophilic digestion this did not appear to be the case: apart from a slight delay in the onset of VFA accumulation and a lower rate of accumulation in TE supplemented digesters, little difference was observed between digesters receiving or not receiving TE supplementation. Good volumetric and specific gas productions were observed for a period of $\sim 70$ days in non-supplemented and $\geq 158$ days in TE supplemented digesters, despite the increasing VFA concentrations. All of the digesters appeared to be working in a meta-stable state, however, and were sensitive to small changes in operational conditions (in 
this case an interruption in feeding), which led to a rapid rise in the IA/PA ratio, $\mathrm{pH}$ reduction and cessation of gas production.

\section{Acknowledgements}

This work was carried out with support from the Government of Thailand and from the European Union FP7 VALORGAS project no. 3241334 (www.valorgas.soton.ac.uk).

\section{References}

[1] Banks, C. J., Chesshire, M., Stringfellow, A.: A pilot-scale comparison of mesophilic and thermophilic digestion of source segregated domestic food waste. Water Science and Technology 58, 1475-1481 (2008).

[2] Neiva Correia, C., Vaz, F., Torres, A.: Anaerobic digestion of biodegradable waste operational and stability parameters for stability control. In: 5th IWA International Symposium on AD of Solid Wastes and Energy Crops, Tunisia (2008).

[3] Banks C.J., Chesshire, M., Heaven S., Arnold, R.: Anaerobic digestion of source segregated domestic food waste: performance assessment by mass and energy balance. Bioresource Technology 102(2), 612-620 (2011).

[4] Park, Y., Hong, F., Cheon, J., Hikada, T., Tsuno, H.: Comparison of thermophilic anaerobic digestion characteristics between single-phase and two-phase systems for kitchen garbage treatment. Journal of Bioscience and Bioengineering 105(1), 48-54 (2008)

[5] Zhang Y., Banks C.J., Heaven S.: Anaerobic digestion of two biodegradable municipal waste streams. Journal of Environmental Management 104, 166-174 (2012). doi:10.1016/j.jenvman.2012.03.043

[6] Dinsdale, R.M., Hawkes, F.R., Hawkes, D.L.: The mesophilic and thermophilic anaerobic digestion of coffee waste containing coffee grounds. Water Research 30(2), 371-377 (1996).

[7] Kim, M., Ahn, Y.-H., Speece, R.E.: Comparative process stability and efficiency of anaerobic digestion; mesophilic vs. thermophilic. Water Research, 36, 4369-4385 (2002).

[8] Banks C.J.: Anaerobic digestion of solid and high nitrogen content fractions of slaughterhouse wastes. In: Environmentally Responsible Food Processing. AIChE Symposium Series 90, 103-109 (1994). 
[9] Salminen, E.A., Rintala, J.A.: Semi-continuous anaerobic digestion of solid poultry slaughterhouse waste: effect of hydraulic retention time and loading. Water Research 36(13): 3175-3182 (2002).

[10] Hejnfelt, A., Angelidaki, I.: Anaerobic digestion of slaughterhouse by-products. Biomass and Bioenergy 33(8), 1046-1054 (2009).

[11] Khanal, S.K.: Anaerobic Biotechnology for Bioenergy Production: Principles and Applications, Singapore, Wiley-Blackwell (2008).

[12] McCarty, P.L.: Anaerobic waste treatment fundamentals. Public Works 95, 91-94 (1964).

[13] Angelidaki, I., Ahring, B.K.: Anaerobic thermophilic digestion of manure at different ammonia loads: Effect of temperature. Water Research 28(3), 727-731 (1994).

[14] Borja, R., Sanchez, E., Weiland, P.: Influence of ammonia concentration on thermophilic anaerobic digestion of cattle manure in upflow anaerobic sludge blanket (UASB) reactors. Process Biochemistry 31(5), 477-483 (1996).

[15] Angelidaki, I., Ellegaard, L., Ahring, B.K.: Applications of Anaerobic Digestion Process in Biomethanation II. Springer. Germany (2003).

[16] Angelidaki, I., Ahring, B.K.: Thermophilic anaerobic digestion of livestock waste: the effect of ammonia. Applied Microbiology and Biotechnology 38(4), 560-564, (1993).

[17] Feng, X.M., Karlsson, A., Svensson, B.H., Bertilsson, S.: Impact of trace element addition on biogas production from food industrial waste - linking process to microbial communities. FEMS Microbiology Ecology 74(1), 226-240 (2010).

[18] Banks C.J., Zhang Y., Jiang Y., Heaven S.: Trace element requirements for stable food waste digestion at elevated ammonia concentrations. Bioresource Technology 104, $127-$ 135 (2012)

[19] Zhang, L., Jahng, D.: Long-term anaerobic digestion of food waste stabilized by trace elements. Waste Management 32(8), 1509-1515 (2012).

[20] Qiang, H., Lang D.-L., Li, Y.-Y.: High-solid mesophilic methane fermentation of food waste with an emphasis on Iron, Cobalt, and Nickel requirements. Bioresource Technology 103(1), 21-27 (2012).

[21] Walker, M., Zhang, Y., Heaven, S., Banks C.J.: Potential Errors in the Quantitative Evaluation of Biogas Production in Anaerobic Digestion Processes. Bioresource Technology 100(24), 6339-6346 (2009). 
[22] APHA: Standard methods for the examination of water and wastewater. $21^{\text {st }}$ edition, American Public Health Association, American Water Works Association, Water Environment Federation, Washington DC, USA (2005).

[23] Ripley, L.E., Boyle, W.C., Converse, J.C.: Improved alkalimetric monitoring for anaerobic digestion of high-strength wastes. Journal (Water Pollution Control Federation), 58(5), 406-411 (1986).

[24] Hansen, K.H., Angelidaki, I., Ahring B.K.: Anaerobic digestion of swine manure: inhibition by ammonia. Water Research 32(1), 5-12 (1998).

[25] Defra: Optimising processes for the stable operation of food waste digestion. Technical Report, Defra project code WR1208. (2010). Available http://sciencesearch.defra.gov.uk/Default.aspx ?Menu=Menu\&Module=More $\&$ Location= None\&Completed=0\&ProjectID=16690, accessed July 2014 .

[26] VALORGAS: Compositional analysis of food waste from study sites in geographically distinct regions of Europe. Deliverable D2.1, FP7 VALORGAS project (2011). Available http://www.valorgas.soton.ac.uk/deliverables.htm, accessed March 2014.

[27] Moore, D.R.J.: The Anna Karenina principle applied to ecological risk assessments of multiple stressors. Human and Ecological Risk Assessment: An International Journal, 7 , 231-237 (2001).

[28] Sung, S., Liu, T.: Ammonia inhibition on thermophilic anaerobic digestion. Chemosphere 53, 43-52 (2003).

[29] Ferrer, I., Vázquez, F., Font, X.: Long term operation of a thermophilic anaerobic reactor: Process stability and efficiency at decreasing sludge retention time. Bioresource Technology 101, 2972-2980 (2010).

[30] Uemura, S.: Mineral Requirements for Mesophilic and Thermophilic Anaerobic Digestion of Organic Solid Waste. Int. J. Environ. Res. 4, 33-40 (2010).

[31] Speece, R.E.: Anaerobic Biotechnology and Odor/Corrosion Control for Municipalities and Industries, Tennessee, USA, Archaea Press (2008).

[32] Qiang, H., Niu, Q., Chi, Y., Li, Y.: Trace metals requirements for continuous thermophilic methane fermentation of high-solid food waste. Chemical Engineering Journal 222(0) 330-336 (2013).

[33] Hashimoto, A.G.: Ammonia inhibition of methanogenesis from cattle wastes. Agricultural Wastes 17, 241-261 (1986). 
Table 1 Food waste characteristics

\begin{tabular}{|c|c|c|c|c|c|c|c|c|}
\hline Parameter & Unit & This study & Luton, $\mathrm{UK}^{\mathrm{a}}$ & Hackney, UK ${ }^{\mathrm{a}}$ & Ludlow, UK ${ }^{\text {a }}$ & Eastleigh, $\mathrm{UK}^{\mathrm{b}, \mathrm{c}}$ & Forssa, Finland ${ }^{b}$ & Treviso, Italy ${ }^{\mathrm{b}}$ \\
\hline $\mathrm{TS}$ & $(\% \mathrm{WW})$ & $23.65 \pm 0.38$ & $23.70 \pm 0.06$ & $25.74 \pm 0.18$ & $23.74 \pm 0.08$ & $27.01 \pm 0.11$ & $27.02 \pm 0.12$ & $27.47 \pm 0.03$ \\
\hline VS & $(\% \mathrm{WW})$ & $21.99 \pm 0.49$ & $21.84 \pm 0.10$ & $23.47 \pm 0.31$ & $21.71 \pm 0.09$ & $24.92 \pm 0.08$ & $24.91 \pm 0.05$ & $23.60 \pm 0.09$ \\
\hline VS/TS & & $92.96 \pm 1.00$ & $91.28 \pm 0.20$ & $91.17 \pm 0.91$ & $91.44 \pm 0.39$ & $92.26 \pm 0.31$ & $92.26 \pm 0.26$ & $86.60 \pm 0.40$ \\
\hline COD & $\left(\mathrm{g} \mathrm{kg}^{-1} \mathrm{TS}\right)$ & $998 \pm 71$ & & & & & & \\
\hline TKN & $\left(\mathrm{g} \mathrm{kg}^{-1} \mathrm{WW}\right)$ & $7.44 \pm 0.02$ & $7.39 \pm 0.02$ & $8.06 \pm 0.08$ & $8.12 \pm 0.09$ & $7.53 \pm 0.13$ & $6.45 \pm 0.1$ & $7.02 \pm 0.1$ \\
\hline Cobalt (Co) & $\left(\mathrm{mg} \mathrm{kg}^{-1} \mathrm{TS}\right)$ & 0.1 & $0.07 \pm 0.01$ & $0.35 \pm 0.19$ & $<0.25$ & $0.15 \pm 0.03$ & $1.85 \pm 0.2$ & $4.72 \pm 0.2$ \\
\hline $\operatorname{Iron}(\mathrm{Fe})$ & $\left(\mathrm{mg} \mathrm{kg}^{-1} \mathrm{TS}\right)$ & 89 & $148 \pm 1$ & $175 \pm 58$ & 229 & $111 \pm 1$ & $538 \pm 32$ & $1558 \pm 72$ \\
\hline Manganese (Mn) & $\left(\mathrm{mg} \mathrm{kg}^{-1} \mathrm{TS}\right)$ & 92 & $97.7 \pm 1.6$ & $94.5 \pm 4.1$ & $85 \pm 14$ & $86.5 \pm 2.5$ & $41.1 \pm 0.2$ & $84.6 \pm 1.3$ \\
\hline Molybdenum (Mo) & $\left(\mathrm{mg} \mathrm{kg}^{-1} \mathrm{TS}\right)$ & 0.37 & $1.1 \pm 0.2$ & $1.2 \pm 0.2$ & $0.46 \pm 0.05$ & $2.8 \pm 0.6$ & $4.3 \pm 0.4$ & $8.7 \pm 0.3$ \\
\hline Selenium $(\mathrm{Se})$ & $\left(\mathrm{mg} \mathrm{kg}^{-1} \mathrm{TS}\right)$ & 0.17 & $1.2 \pm 0.6$ & $0.4 \pm 0.3$ & $<0.30$ & $0.42 \pm 0.20$ & & \\
\hline Elemental composition & & & & & & & & \\
\hline $\mathrm{N}$ & $(\% \mathrm{TS})$ & $3.00 \pm 0.01$ & $3.12 \pm 0.01$ & $3.13 \pm 0.03$ & $3.42 \pm 0.04$ & $2.91 \pm 0.05$ & $2.46 \pm 0.03$ & $2.58 \pm 0.05$ \\
\hline $\mathrm{C}$ & $(\% \mathrm{TS})$ & $52.3 \pm 1.1$ & $51.2 \pm 1.2$ & $51.3 \pm 0.2$ & $48.3 \pm 1.0$ & $48.8 \pm 0.9$ & $49.4 \pm 0.04$ & $47.2 \pm 0.01$ \\
\hline $\mathrm{H}$ & $(\% \mathrm{TS})$ & $6.89 \pm 0.16$ & $6.56 \pm 0.04$ & $6.67 \pm 0.13$ & $5.53 \pm 0.63$ & $6.37 \pm 0.19$ & - & - \\
\hline
\end{tabular}

${ }^{\mathrm{a}}$ reference [24]

${ }^{\mathrm{b}}$ reference [25]

${ }^{\mathrm{c}}$ trace element concentrations are from currently unpublished VALORGAS data 


\section{Figure captions}

Figure 1. Monitoring parameters in all digesters during start-up period: (a) $\mathrm{pH}$, (b) total ammonia nitrogen, (c) IA/PA ratio, (d) specific methane production, from day 1-50; (e) acetic and propionic acid concentrations from day 0-30.

Figure 2. VFA profiles during period of OLR increase from day 1-50 in (a) TE-2-A, (b) TE-2-B, (c) TE-3-A, (d) TE-3-B, (e) TE-4-A, (f) TE-4-B (with TE supplementation); and (g) noTE-2-A and (h) noTE-2-B (without TE supplementation).

Figure 3. Monitoring parameters in all digesters from day 0-250; (a) total ammonia nitrogen, (b) total alkalinity; (c) volatile solids as \% of wet weight, (d) volatile solids as \% of total solids. (Note: solids measurements taken only during period of regular feeding to day 158)

Figure 4. Monitoring parameters in all digesters from day 0-250: (a) volumetric methane production in TE-2-A\&B, TE-3-A\&B and TE-4-A\&B; (b) specific methane production in TE-2$\mathrm{A} \& \mathrm{~B}, \mathrm{TE}-3-\mathrm{A} \& \mathrm{~B}$ and TE-4-A\&B; (c) biogas methane content in all digesters; (d) specific methane production in noTE-2-A\&B; (e) IA/PA in all digesters; (f) $\mathrm{pH}$ in all digesters; (g) total VFA in all digesters; (h) FAN in all digesters.

Figure 5. Digester OLR and VFA profile from day 0-250: a) OLR $3+$ TE (TE-3-A), b) OLR $3+$ TE (TE-3-B), c) OLR 4 + TE (TE-4-A), d) OLR 4 + TE (TE-4-B), e) OLR 2 + TE (TE-2-A), f) OLR 2 + TE (TE-2-B), g) OLR 2 no TE (noTE-2-A), h) OLR 2 no TE (noTE-2-B).

Figure 6. VFA concentrations in TE supplemented and unsupplemented digesters at OLR $2 \mathrm{~g}$ $\mathrm{VS}^{-1}$ day $^{-1}$ between day 70-140, with trend lines showing rates of increase. 